\title{
Investigation of Relationship between Comorbid Factors and Excessive Dynamic Airway Collapse and Frequency of Hospitalization in Frequently Hospitalized COPD Patients
}

\author{
Tülay Yarkın ${ }^{1}$, Meltem Ağcaㄹ, Göksan Acar², Gökhan Göl ${ }^{3}$, Fatma Tokgöz ${ }^{1}$, Reha Baran \\ ${ }^{1}$ Clinic of Chest Diseases, Süreyyapaşa Chest Diseases and Thoracic Surgery Training and Research Hospital, İstanbul \\ ${ }^{2}$ Clinic of Chest Diseases, Van Lokman Hekim Hospital, Van \\ ${ }^{3}$ Department of Cardiology, Süreyyapaşa Chest Diseases and Thoracic Surgery Training and Research Hospital, İstanbul \\ ${ }^{4}$ Clinic of Chest Diseases, Aclbadem Fulya Hospital, İstanbul
}

\begin{abstract}
Objective: "Frequent hospitalization" is defined as at least 2 hospitalizations per year in chronic obstructive pulmonary disease (COPD). However, we witness hospitalizations at 2-3-month intervals in some patients in our clinical practice. In our study, the factors considered to be associated with frequent hospitalizations were investigated in a selected patient group.

Methods: Thirty-four COPD patients being hospitalized at least twice per year were included in the study. The patients' demographic features, laboratory findings, physical activity scores, comorbidities, and respiratory functions were recorded. They underwent transthoracic echocardiography and fiberoptic bronchoscopy (FOB). The patients were categorized as Group 1 (patients hospitalized twice per year) and Group 2 (patients hospitalized more than twice per year). These groups were compared with regard to parameters considered to increase the frequency of hospitalization.

Results: Twenty-eight (82\%) of the patients were male. The mean age was $65 \pm 8$ (46-82) years, and the mean hospitalization number was $3.3 \pm 1.3(2-6)$. There were 12 patients in Group 1 and 22 patients in Group 2. The rates of being in advanced age, showing lower physical activity, being in advanced stage, having disease for more than 10 years, and using a nebulizer and oxygen at home were found to be significantly higher in Group 2 than in Group $1 . \mathrm{FEV}_{1}$ (expected \%) level was $47.9 \%$ in Group 2, while it was $56 \%$ in Group 1 ( $\left.\mathrm{p}=0.003\right)$. The number of comorbidities was approximately 1.5 in Group 1 and 2.7 in Group $2(p=0.014)$. Pulmonary hypertension $(n=11)$ and heart failure $(n=10)$ were identified only in Group $2(p=0.003, p=0.006)$. Excessive dynamic airway collapse (EDAC) was detected in $17(50 \%)$ patients through

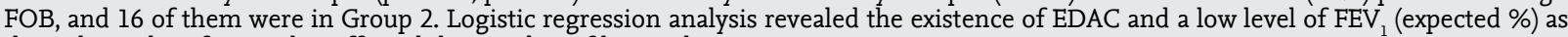
the independent factors that affected the number of hospitalizations.
\end{abstract}

Conclusion: It was suggested that the existence of EDAC and decreased $\mathrm{FEV}_{1}$ can increase the frequency of hospitalization in COPD patients who are hospitalized frequently.

Keywords: Comorbidity, COPD, excessive dynamic airway collapse

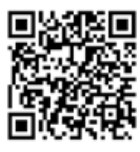

Received Date: 10.03.2014 Accepted Date: 04.08.2014

Available online date: 27.10.2014

Address for correspondence

Tülay Yarkın, Clinic of Chest Diseases, Süreyyapaşa Chest Diseases and Thoracic Surgery Training and Research Hospital, İstanbul, Turkey

E-mail: yarkint@superonline.com

(C) Copyright 2014 Turkish Respiratory Society (TRS) Eurasian J Pulmonol 2014

DOI: 10.5152/ejp.2014.66934

-Available online at www.eurasianjpulmonol.com

\section{INTRODUCTION}

The exacerbation is an important cause of morbidity and mortality in chronic obstructive pulmonary disease (COPD) and often leads to hospitalization. The frequency of exacerbations, reported to range from 0.5 to 3.5 per year, is related to the stage of the disease, and as the number increases, the progression of the disease is affected in a negative way $(1,2)$. In the Global Initiative for Chronic Obstructive Lung Disease (GOLD) guideline, the exacerbations frequency of the disease was stated as 2.6 for stage 2 patients and 3.4 for stage 3 patients (3).

Our hospital is a branch hospital providing services for a great part of the Anatolian side of Istanbul. Most of the hospitalized patients have a diagnosis of COPD. It was observed that some patients were hospitalized more than twice in a year, and they had lengthy medical records. In fiberoptic bronchoscopy (FOB) examinations performed for various reasons, the frequent presence of excessive dynamic airway collapse (EDAC) in these patients caught our attention.

Excessive dynamic airway collapse is a central airway disorder that often accompanies COPD but is diagnosed rarely. It is characterized by a reduction of more than $50 \%$ in the cross-sectional area of the tracheal lumen during expiration due to flaccidity of the supporting tracheal cartilage (4). The bronchoscopic appearance of EDAC is accepted to be the "gold standard" for diagnosis. Excessive dynam- 
ic airway collapse is classified as tracheobronchomalacia (TBM) and tracheomalacia (TM) according to localization. Saber-sheath trachea is a form based on morphology. In this form, the coronal diameter of the trachea decreases, while the sagittal diameter increases, and the characteristic shape of the saber-sheath appears (4-8). The incidence of excessive dynamic airway collapse was reported to be $14 \%$ in patients who underwent $\mathrm{FOB}$ due to chronic cough, $5 \%$ in patients having any respiratory complaints, $13 \%$ in patients with a known pulmonary disease, and $44 \%$ in patients with chronic bronchitis (9-12). In the studies conducted, a rate of $57 \%$ was reported for the coexistence of COPD and EDAC (13). It is controversial whether EDAC that is seen in COPD is a complication of the disease or whether it is a comorbidity that accompanies COPD. However, it is believed that it plays an important role in the progression of COPD.

There are many studies suggesting that comorbid factors and factors, such as advanced age and low $\mathrm{FEV}_{1}$, increase the frequency of hospitalization and mortality (14-16). On the other hand, we could not reach a study investigating the effect of EDAC on the frequency of hospitalization, which has a proven direct effect on the prognosis and morbidity of the disease and which has an important place in the management of COPD. Therefore, our study was conducted in order to investigate the presence of EDAC in addition to the comorbid factors considered to influence frequent hospitalization.

\section{METHODS}

Thirty-four patients who were followed up in our inpatient clinic between January 2009 and January 2010, diagnosed with COPD in accordance with the GOLD guideline, and hospitalized twice or more within the last year were evaluated in this study. These 34 patients were in a stable condition. Their infection markers were negative [absence of purulent phlegm, fever, leukocytosis in the complete blood count, increased C-reactive protein (CRP), and infiltration in chest radiography], and they did not have respiratory acidosis in their arterial blood gas (ABG). Also, ethics committee approval was obtained for the study.

Detailed medical histories of the patients were taken. Their physical activity states and previous medical treatments [use of corticosteroid, long-term oxygen therapy at home (LTOT), use of nebulizer, bronchodilator therapies] were recorded. Peripheral blood examination, ABG analysis, and pulmonary imaging were performed, and pulmonary function test (PFT) was applied.

The values of the PFT carried out within the last year were taken as the basis in the study. For the patients who did not undergo PFTs in the last year, new PFTs were performed using a spirometry device (Spirolab S/N A 23, MIR Medical, Rome, Italy). The values were evaluated as absolute value and the percentage of the expected value for the patient's age and height. The stage of chronic obstructive pulmonary disease was determined according to PFT findings (3).

Body mass index (BMI) was calculated as the ratio of weight to the square of height $\left(\mathrm{m}^{2}\right)$ and categorized into 4 groups in accordance with the recommendations of the World Health Organization (WHO) (17). Accordingly, patients having a BMI lower than 18.5 were accepted to be underweight (cachexia), patients with a BMI of 18.5 to 24.9 were accepted to be optimal weight, those with a BMI of 25 to 30 were accepted to be overweight, and those with a BMI above 30 were accepted as obese.
Right and left heart functions were evaluated through transthoracic echocardiography (TTE) (MyLab ${ }^{\text {TM}} 40$, Esaote, Genoa, Italy), performed by a cardiologist. The patients whose ejection fraction values were above 55\% were considered to have normal left ventricular function, but the ones whose mean pulmonary artery pressure (PAP) was above $25 \mathrm{~mm} \mathrm{Hg}$ were accepted to be pulmonary hypertension (PHT) patients $(18,19)$.

All patients who were included in the study underwent FOB (BF1T60, Olympus, Fukushima, Japan) in the bronchoscopy laboratory of our service. They were administered sedation (midazolam 0.01$0.03 \mathrm{mg} / \mathrm{kg}$, IV) before the process. During the process, oxygen was given through the nasal way, and vital findings were monitored. The existence of EDAC was evaluated by the physician who performed the procedure and was recorded, with its localization. Development of collapse that reduced the airway patency at a rate of more than $50 \%$ during expiration was defined as EDAC. Detection of EDAC only in the trachea was considered TM, and detection in one or two bronchus systems, in addition to the trachea, was evaluated to be TBM (5). Cases with a narrowed coronal diameter of the trachea but widened sagittal diameter were defined as "saber-sheath trachea" (6).

In order to determine the risk for anxiety and depression in the patients, the "Hospital Anxiety and Depression Scale" was employed $(20,21)$.

The presence of non-COPD diseases that were diagnosed through the examinations performed (physical examination, laboratory tests, imaging techniques), based on the patient's own statement, and diagnosed by another health center was considered to be comorbid conditions. The values of hemoglobin below $13 \mathrm{~g} / \mathrm{dL}$ in males and below $12 \mathrm{~g} / \mathrm{dL}$ in females were evaluated as anemia. Cardiovascular diseases were confirmed by a cardiologist. Systolic blood pressure above $140 \mathrm{mmHg}$ and diastolic blood pressure above $90 \mathrm{mmHg}$ were accepted as arterial hypertension. Gastroesophageal reflux (GER), peptic ulcer, osteoporosis, diabetes mellitus (DM), hypertension (HT), coronary artery disease, obstructive sleep apnea syndrome (OSAS), and Parkinson's disease were recorded as comorbidities.

Physical activity measurement was performed using the International Physical Activity questionnaire developed by the International Group for Consensus of Physical Activity Measurements and standardized according to the definitions of physical activity in different countries with different sociocultural perspectives. In the short form of the questionnaire, the activities are divided into three groups-mild, moderate, and hard-and the frequency and duration of each activity are questioned. Each activity has a metabolic equivalent (MET) described in the literature. The questionnaire was given to all patients included in the study. Daily activities were summated in minutes, and weekly values were obtained. Mild activities were multiplied by 3.3, hard activities were multiplied by 4.0 , and very hard activities were multiplied by 8.0. Total MET was calculated by adding up these three values. Patients with a MET value below 600 $\mathrm{kcal} / \mathrm{min}$ were evaluated to be inactive, the ones with a MET value of 600 to $3000 \mathrm{kcal} / \mathrm{min}$ were considered to be moderately active, and the ones with a MET value above $3000 \mathrm{kcal} / \mathrm{min}$ were evaluated as over-active $(22,23)$.

The cases were put into two groups-patients hospitalized twice per year (Group 1) and patients hospitalized more than twice per year 
(Group 2-and a comparative analysis was performed for evaluating the data obtained.

\section{Statistical Analysis}

While evaluating the findings of the study, Statistical Package for Social Sciences (SPSS) software, version 16.0 (SPSS, Chicago, IL, USA) was used for the statistical analyses. In addition to descriptive statistics (frequency, percentage, mean, standard deviation), Pearson chi-square test was used for comparing qualitative data. In comparison of quantitative data, Kruskal-Wallis test was employed for the parameters not displaying a normal distribution, and Mann-Whitney U-test was used for identification of the group causing a difference. The results were evaluated with $95 \%$ confidence intervals and at a significance level of $p<0.05$. The factors affecting the frequency of hospitalization were investigated by logistic regression analysis using the "stepwise backward" method.

\section{RESULTS}

Twenty-eight of 34 patients included in the study were male (82\%), and the mean age was $65 \pm 9(46-82)$ years. The mean cigarette use was found to be $40 \pm 23$ packs-year. The number of hospitalizations in a year was $2-6$, and the mean was $3.3 \pm 1.3$. The level of physical activity was low in 15 patients (44\%). Six patients were cachectic, and 5 were obese, according to BMI. In the spirometric evaluation, the mean $\mathrm{FEV}_{1}$ was $1.3 \pm 0.4 \mathrm{~L}$, and $\mathrm{FEV}_{1}$ (predicted \%) was $50.8 \pm 7.9$. It was found that 22 patients had COPD for more than 10 years. In accordance with the GOLD guideline, 20 patients were stage 2, 10 patients were stage 3 , and 4 patients were stage 4 .

Of the patients, $88 \%(n=30)$ had at least one comorbid disease diagnosed through the examinations and/or diagnosed by a physician, based on their own statement, and the most common comorbid diseases were systemic HT $(n=16)$, GER $(n=14)$, PHT $(n=11)$, and heart failure $(n=10)$, respectively. The "Hospital Anxiety Depression Scale" revealed anxiety in 5 patients and depression symptoms in 3 patients. When comorbid factors were classified according to GOLD staging, the incidence of heart failure and OSAS increased in parallel with increased stage. The comparison of comorbid factors in accordance with the stage of COPD is shown in Table 1.

The patients in our study were categorized into two groups: patients with 2 hospitalizations per year (Group 1) and patients with more than 2 hospitalizations (Group 2). The comparison of the groups according to the variables is summarized in Table 2. In Group 1, there were 12 patients, and there were no female patients. The mean age was 61 years. Group 2 included 22 patients ( 6 females, 16 males), and the mean age was 67.6 years, which was significantly higher than in Group 1 ( $p=0.031)$. No significant relationship was found between gender and cigarette packs-year and the number of hospitalizations (respectively, $\mathrm{p}=0.055, \mathrm{p}=0.221$ ). The $\mathrm{FEV}_{1}$ and $\mathrm{FEV}_{1} \%$ values were $1.58 \mathrm{~L}$ and $56 \%$ in Group 1 and $1.21 \mathrm{~L}$ and $47.9 \%$ in Group 2. Accordingly, there was a negative relationship between the frequency of hospitalization and FEV $(p=0.008)$ and $\mathrm{FEV}_{1} \%(p=0.003)$. Forty percent of the patients with GOLD stage 2 and all of the patients in stage 3 and 4 were included in Group $2(p=0.001)$. Of the patients having the disease for more than 10 years, 13.6\% was in Group 1 and $86.4 \%$ was in Group $2(p=0.001)$. All of the patients with low physical activity level were involved in Group 2.

The mean comorbidity number was 1.5 in Group 1, while it was 2.7
Table 1. Comparison of comorbidities according to COPD stage

\begin{tabular}{|l|c|c|c|c|}
\hline Pulmonary hypertension & $\begin{array}{c}\text { Stage 2 } \\
(\mathbf{n}=20)\end{array}$ & $\begin{array}{c}\text { Stage 3 } \\
(\mathbf{n}=10)\end{array}$ & $\begin{array}{c}\text { Stage 4 } \\
(\mathbf{n}=4)\end{array}$ & $\mathbf{p}$ \\
Heart failure & 1 & 7 & 4 & $<0.001$ \\
OSAS & 0 & 5 & 0 & 0.001 \\
Diabetes mellitus Type 2 & 4 & 1 & 2 & 0.246 \\
Gastroesophageal reflux & 6 & 6 & 2 & 0.269 \\
Coronary artery disease & 2 & 0 & 0 & 0.475 \\
Hypertension & 8 & 6 & 2 & 0.581 \\
Depression & 0 & 3 & 0 & 0.495 \\
OSAS: Obstructive sleep apnea syndrome & & & $<0.001$ \\
\hline
\end{tabular}

Table 2. Comparison of variables according to frequency of hospitalizations per year

\begin{tabular}{|c|c|c|c|}
\hline Characteristics & $\begin{array}{c}\text { Group } 1 \\
(n=12)\end{array}$ & $\begin{array}{c}\text { Group } 2 \\
(n=22)\end{array}$ & p \\
\hline Gender (n): Female & 0 & 6 & 0.055 \\
\hline Male & 12 & 16 & \\
\hline Age (mean) & 61.0 & 67.6 & 0.031 \\
\hline Smoking (packs-year) (mean) & 33.4 & 43.6 & 0.221 \\
\hline Stage 2 COPD & 12 & 8 & 0.001 \\
\hline Stage 3 and 4 COPD & & 14 & \\
\hline Duration of COPD: $<10$ years & 9 & 3 & 0.001 \\
\hline Duration of COPD: $>10$ years & 3 & 19 & \\
\hline $\mathrm{FEV}_{1}$ mean $(\mathrm{L})$ & 1.58 & 1.21 & 0.008 \\
\hline $\mathrm{FEV}_{1}$ predicted $\%$ & 56.0 & 47.9 & 0.003 \\
\hline \multicolumn{4}{|l|}{ Physical activity } \\
\hline Low & 0 & 15 & $<0.000$ \\
\hline Moderate and high & 12 & 7 & \\
\hline Comorbidity (mean) & 1.5 & 2.7 & 0.014 \\
\hline Pulmonary hypertension & 0 & 11 & 0.003 \\
\hline Heart failure & 0 & 10 & 0.006 \\
\hline Use of nebulizer & 1 & 20 & $<0.000$ \\
\hline Use of LTOT & 1 & 12 & 0.009 \\
\hline Use of ICS & 11 & 19 & 0.556 \\
\hline Presence of EDAC & 1 & 16 & $<0.000$ \\
\hline
\end{tabular}

in Group 2. A change was detected in the order of frequently seen comorbidities between the two groups. Pulmonary hypertension and heart failure were not observed in Group 1 but were seen in $11(\mathrm{p}<0.001)$ and $10(\mathrm{p}<0.001)$ patients, respectively, in Group 2. In the patients using long-term oxygen therapy and nebulizer, the frequency of hospitalization was higher than in those not using them $(p<0.01, p<0.000$, respectively). The rates of administration of bron- 

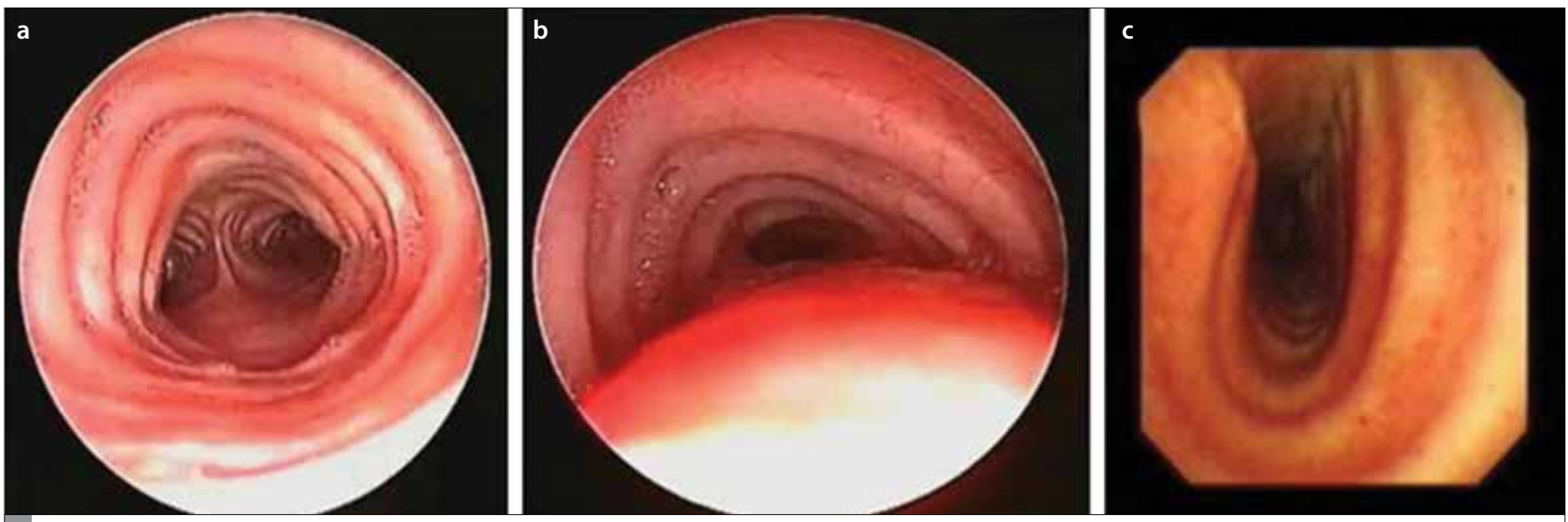

Figure 1. a-c. Normal endobronchial system and sample images of EDAC patients: normal endobronchial system (a), tracheomalacia (b), and saber-sheath trachea (c)

Table 3. Bronchoscopy results according to group

\begin{tabular}{|l|c|c|c|}
\hline Tracheomalacia & $\begin{array}{c}\text { Group 1 } \\
\text { (n) }\end{array}$ & $\begin{array}{c}\text { Group 2 } \\
\text { (n) }\end{array}$ & p \\
\hline Tracheobronchomalacia & 0 & 2 & \\
Saber-sheath trachea & 0 & 6 & \\
Hypersecretion & 3 & 4 & 0.67 \\
\hline
\end{tabular}

chodilator therapy with a single drug or multiple drugs, use of longor short-acting bronchodilator, and use of inhaler corticosteroid (ICS) were similar in both groups $(\mathrm{p}>0.05)$.

The bronchoscopic evaluation carried out for the patients included in the study revealed EDAC in 17 patients (50\%) (Figure 1). The presence of EDAC was observed in 11 male patients and in all female patients. Tracheobronchomalacia $(n=9)$ was the most common cause, with saber-sheath trachea $(n=6)$ and tracheomalacia $(n=2)$ observed less frequently. No major complication developed during and after bronchoscopy. The bronchoscopic findings are shown in Table 3. Excessive dynamic airway collapse was found in 16 of 22 patients included in Group 2 (72\%), but it was seen in only 1 patient (8.3\%) in Group 1.

For independent variables affecting the number of hospitalizations, regression analysis was performed with stepwise method. The model, generated using statistically significant parameters, was found to be strong for the analysis $\left(F=20.823 ; p<0.001 ; R^{2}=0.598\right)$. The presence of EDAC and a low level of FEV (predicted \%) value were identified as independent factors that affected the frequency of hospitalization ( $p<0.05, p<0.01$, respectively). It was revealed that other variables $\left(F_{1}, \mathrm{~mL}, \mathrm{FVC}, \mathrm{FEV}_{1} / \mathrm{FVC}\right.$, GOLD stage, MRCE) did not influence the frequency of hospitalization ( $p>0.05)$.

\section{DISCUSSION}

In our study, the factors significantly affecting the frequency of hospitalization were evaluated together in COPD cases, and the presence

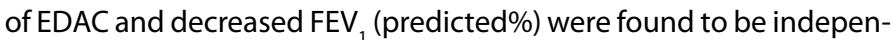
dent factors contributing to the frequency of hospitalization. It has been stated in many articles that $\mathrm{FEV}_{1}$ is significant in terms of both prognosis and hospitalization frequency. However, the relationship between EDAC and hospitalization frequency was first suggested in this study. In our series, EDAC was detected in $72 \%$ of the patients in Group 2 but in only 1 patient (8.3\%) in Group 1. In the presence of EDAC, adequate expectoration can not be reached due to complete or almost complete collapse during challenging expiration and coughing. Thus, in EDAC, secretions accumulating in the back can lead to exacerbation and increase the frequency of hospitalization.

In chronic obstructive pulmonary disease, with each exacerbation reported to be associated with a poor prognosis, the risk for longer hospitalization is higher than a previous hospitalization. Moreover, some studies revealed that hospitalization associated with exacerbation in COPD causes the disease to pass to the next advanced stage $(24,25)$. In the study of Garcia-Sanz et al. (26) that was conducted with 239 COPD patients, hospitalization was detected in $71 \%$ of patients in GOLD 3 and 4 stages. Özyılmaz et al. (27) identified a low level of $\mathrm{FEV}_{1}$ as an independent risk factor in frequent exacerbations requiring hospitalization. Cao et al. (28) found that hospitalization frequency was 2-fold higher in patients having COPD for more than 5 years, and a value of $\mathrm{FEV}_{1}$ below $50 \%$ was included among the causes of hospitalization. Similarly, in our study, low FEV (predicted\%) value was detected as an independent risk factor, and it was observed that increased severity of the disease elevated the number of hospitalizations. Three or more hospitalizations per year were recorded for all of GOLD stage 3 and 4 patients.

In our series, the difference in gender did not vary for the patients with frequent hospitalization, but the mean age was found to be significantly higher in Group 2. There are some studies suggesting that these two parameters affect frequent hospitalization, as well as studies suggesting the opposite (29-31). Frequent hospitalization in advanced age can be related to decreased respiratory functions associated with age. There are some studies showing that low BMI increases frequent hospitalization and mortality $(29,31,32)$. Although a direct relationship was not found between low BMI and the number of hospitalizations, all of the cachectic patients were situated in Group 2 in our study.

An interesting result of our study was the significant increase in the number of hospitalizations in patients using a nebulizer and LTOT at 
home. Almagro et al. (15), in their study conducted with 606 patients, found the frequency of hospitalization to be higher in the patients $(n=237)$ receiving LTOT, compared to other patients. These results, similar to ours, can be explained by ineffective oxygen therapy at home, the nebulizer device becoming an infection source after a while, and side effects resulting from frequent use of bronchodilator medications. On the other hand, the fact that patients using LTOT and nebulizer device had advanced-stage COPD and thus were situated in a group with a higher number of hospitalizations should be taken into consideration.

Some studies reported that there was an increase in frequent hospitalizations and mortality due to long-term oral corticosteroid use, and it was defended that this was resulted from side effects associated with steroid use $(33,34)$. Contrary to these studies, some results showing that the use of inhaler and systemic corticosteroid did not affect hospitalization were reported (35). In our study, there was no patient using long-term systemic corticosteroid, and the relationship between the use of inhaler steroid and frequent hospitalization was found to be insignificant. However, it is known that patients using a nebulizer often prefer the nebular form of corticosteroids. Therefore, it should be considered that frequent hospitalizations in patients using nebulizer can be associated with the side effects of corticosteroids.

One of the other important factors increasing the frequency of hospitalization is known to be comorbid diseases. The most common comorbid diseases in COPD are cardiovascular events, malnutrition, dysfunction and loss of skeletal muscles, cachexia, osteoporosis, anemia, lung cancer, GER, DM, metabolic syndrome, OSAS, depression, and anxiety $(36,37)$. Almagro et al. (15) found in their study, published in 2012 , that $71 \%$ of patients requiring hospitalization at their emergency admission had a previous hospitalization, and they emphasized the importance of comorbid diseases. Taşçı et al. (38) evaluated 81 COPD patients who were hospitalized, and the presence of DM in 13 patients having 4 and 6 hospitalizations was thought to be remarkable. In our series, $88 \%$ of the patients had at least one comorbidity, and the most common comorbidities were HT, GER, PHT, heart failure, and type $2 \mathrm{DM}$, respectively. Pulmonary hypertension and heart failure were detected only in Group 2 patients.

The main limitation of our study is the low number of patients. Our hospital is a big branch hospital with a capacity of 605 beds. It is extremely busy, especially during winter, and the mean hospitalization due to a diagnosis of COPD is 340 in a month (39). Thereby, the cases with COPD occupy an important place in our clinical practice, and thus, we gain experience. However, the patients involved in our study were selected among patients only in our service (34 beds). Furthermore, applying of an invasive procedure affected the number of patients in a negative way. The second limitation is the insufficient number of female patients. The higher incidence of the disease in male patients might have resulted from the fact that the rate of smoking was higher in males than in females. Moreover, to say that EDAC was more frequently seen in females can be misleading because of the low number of patients. The third limitation can be that no stage 1 patient was involved in the study. Moreover, the insufficient number of stage 4 patients might have affected the results. However, our study was conducted with a selected patient group, including only the ones with a higher frequency of hospitalization, and they were generally COPD patients in the moderate and severe stages.

\section{CONCLUSION}

In this study, it is remarkable that patients with frequent hospitalizations have different characteristics among them. The findings obtained made us to think that the concept of frequent hospitalizations could be used for more than 2 hospitalizations per year, instead of 2 and over per year, or that the concepts of "frequent hospitalizations" and "very frequent hospitalizations" could be emphasized.

In frequently hospitalized COPD patients, detection of comorbid diseases and application of appropriate treatments for these diseases will facilitate the management of COPD. Furthermore, it is important for clinicians to know that the presence of EDAC is a factor increasing the frequency of hospitalization in COPD patients, and awareness on this issue should be raised. Thus, more detailed examinations will be carried out for the diagnosis, and different treatment options will appear for the disease.

Ethics Committee Approval: Ethics committee approval was received for this study from the local ethics committee.

Informed Consent: Written informed consent was obtained from patients who participated in this study.

Peer-review: Externally peer-reviewed.

Author contributions: Concept - T.Y., R.B., G.A.; Design - T.Y., G.A., R.B.; Supervision - T.Y., M.A., R.B.; Resource - M.A., G.A., F.T.; Materials - G.A., T.Y., R.B., G.G.; Data Collection and/or Processing - G.A., T.Y., R.B.; Analysis and/or Interpretation - T.Y., M.A., G.A.; Literature Review - M.A., G.A., F.T., T.Y.; Writing - T.Y., M.A., G.A.; Critical Review - F.T., G.A., G.G.

Acknowledgements: We thank Selin Alıcı for statistical contribution.

Conflict of Interest: No conflict of interest was declared by the authors.

Financial Disclosure: The authors declared that this study has received no financial support.

\section{REFERENCES}

1. Seemungal TA, Donaldson GC, Bhowmik A, Jeffries DJ, Wedzicha JA. Time course and recovery of exacerbations in patients with chronic obstructive pulmonary disease. Am J Respir Crit Care Med 2000; 161: 1608-13. [CrossRef]

2. Seemungal TA, Donaldson GC, Paul EA, Bestall JC, Jeffries DJ, Wedzicha JA. Effect of exacerbation on quality of life in patients with chronic obstructive pulmonary disease. Am J Respir Crit Care Med 1998; 157: 141822. [CrossRef]

3. Global Initiative for Chronic Obstructive Lung Disease. Global strategy for the diagnosis, management and prevention of chronic obstructive pulmonary disease updated 2010 (www.goldcopd.org).

4. Wright CD. Tracheomalacia. Chest Surg Clin N Am 2003; 13: 349-57. [CrossRef]

5. Carden KA, Boiselle PM, Waltz DA, Ernst A. Tracheomalacia and tracheobronchomalacia in children and adults: an in-depth review. Chest 2005; 127: 984-1005. [CrossRef]

6. Greene R. "Saber-sheath" trachea: relation to chronic obstructive pulmonary disease. AJR Am J Roentgenol 1978; 130: 441-5. [CrossRef]

7. Nuutinen J, Leinonen A. Acquired tracheobronchomalacia. A cineradiographic study with bronchologic correlations. Ann Clin Res 1977; 9: 365-8.

8. Ernst A, Majid A, Feller-Kopman D, Guerrero J, Boiselle P, Loring SH, et al. Airway stabilization with silicone stents for treating adult tracheobronchomalacia: a prospective observational study. Chest 2007; 132: 609-16. [CrossRef]

9. Palombini BC, Villanova CA, Araujo E, Gastal OL, Alt DC, Stolz DP, et al. A pathogenic triad in chronic cough: asthma, postnasal drip syndrome, and gastroesophageal reflux disease. Chest 1999; 116: 279-84. [CrossRef]

10. Jokinen K, Palva T, Sutinen S, Nuutinen J. Acquired tracheobronchomalacia. Ann Clin Res 1977; 9: 52-7. 
11. Ikeda S, Hanawa T, Konishi T, Adachi M, Sawai S, Chiba W et al. Diagnosis, incidence, clinicopathology and surgical treatment of acquired tracheobronchomalacia. Nihon Kyobu Shikkan Gakkai Zasshi 1992; 30: 1028-35.

12. Jokinen K, Palva T, Nuutinen J. Chronic bronchitis. A bronchologic evaluation. ORL J Otorhinolaryngol Relat Spec 1976; 38: 178-86. [CrossRef]

13. Kandaswamy C, Balasubramanian V. Review of adult tracheomalacia and its relationship with chronic obstructive pulmonary disease. Curr Opin Pulm Med 2009; 15: 113-9. [CrossRef]

14. Groenewegen KH, Schols AM, Wouters EF. Mortality and Mortality-Related Factors After Hospitalisation for Acute Exacerbation of COPD. Chest 2003; 124: 459-67. [CrossRef]

15. Almagro P, Cabrera FJ, Diez J, Boixeda R, Ortiz MBA, Murio C, et al. Comorbidities and Short-term Prognosis in Patients Hospitalized for Acute Exacerbation of COPD. Chest 2012; 142: 1126-33. [CrossRef]

16. Bahadori K, FitzGerald JM, Levy RD, Fera T, Swiston J. Risk factors and outcomes associated with chronic obstructive pulmonary disease exacerbations requiring hospitalization. Can Respir J 2009; 16: 43-9.

17. WHO expert consultation. Appropriate body-mass index for Asian populations and its implications for policy and intervention strategies. Lancet 2004; 363: 157-63. [CrossRef]

18. ACC/AHA 2005 Guideline Update for the Diagnosis and Management of Chronic Heart Failure in the Adult A Report of the American College of Cardiology/American Heart Association Task Force on Practice Guidelines. Circulation 2005; 112: 154-235.

19. Chaouat A, Naeije R, Weitzenblum E. Pulmonary hypertension in COPD. Eur Respir J 2008; 32: 1371-85. [CrossRef]

20. Zigmond AS, Snaith PR. The hospital anxiety and depression scale. Acta Psychiatr Scand 1983; 67: 361-70. [CrossRef]

21. Aydemir Ö, Güvenir T, Küey L, Kültür S. Validity and reliability of the Turkish version of hospital anxiety and depression scale. Türk Psikiyatri Dergisi 1997; 8: 280-7.

22. Scoring Protocol, 2005. Available from: www.ipaq.ki.se/IPAQ.

23. Savcı S, Öztürk M, Arıkan H. Physical activity levels of university students. Türk Kardiyoloji Arşivi 2006; 34: 166-72.

24. Fan VS, Curtis R, Tu SP, McDonell MB, Fihn SD. Using quality of life to predict hospitalization and mortality in patients with obstructive lung diseases. Chest 2002; 122: 429-36. [CrossRef]

25. Osman IM, Godden DJ, Friend JA, Legge JS, Douglas JG. Quality of life and hospital re-admission in patients with chronic obstructive pulmonary disease. Thorax 1997; 52: 67-71. [CrossRef]

26. Garcia-Sanz MT, Pol-Balado C, Abellas C, Canvie-Gomez JC, Anton-San- martin D, Gonzalez-Barcala FJ. Factors associated with hospital admission in patients reaching the emergency department with COPD exacerbation. Multidiscip Respir Med 2012; 7: 6. [CrossRef]

27. Ozyilmaz E, Kokturk N, Teksut G, Tatlicioglu T. Unsuspected risk factors of frequent exacerbations requiring hospital admission in chronic obstructive pulmonary disease. Int J Clin Pract 2013; 67: 691-7. [CrossRef]

28. Cao Z, Ong KC, Eng P, Tan WC, Ng TP. Frequent hospital readmissions for acute exacerbation of COPD and their associated factors. Respirology 2006; 11: 188-95. [CrossRef]

29. Garcia-Aymerich J, Farrero E, Felez MA, Izquierdo J, Marrades RM, Anto $J M$, et al. Risk factors of readmission to hospital for a COPD exacerbation: A prospective study. Thorax 2003; 58: 100-5. [CrossRef]

30. Kessler R, Faller M, Fourgaut G, Mennecier B, Weitzenblum E. Predictive factors of hospitalization for acute exacerbation in a series of 64 patients with chronic obstructive pulmonary disease. Am J Respir Crit Care Med 1999; 159: 158-64. [CrossRef]

31. Soler-Cataluna JJ, Martinez-Garcia MA, Roman Sanchez P, Salcedo E, Navarro $M$, Ochando $R$. Severe acute exacerbations and mortality in patients with chronic obstructive pulmonary disease. Thorax 2005; 60: 925-31. [CrossRef]

32. Pouw EM, Ten Velde GP, Croonen BH, Kester AD, Schols AM, Wouters EF. Early non-elective readmission for chronic obstructive pulmonary disease is associated with weight loss. Clin Nutr 2000; 19: 95-9. [CrossRef]

33. Groenewegen KH, Schols AM, Wouters EFM. Mortality and Mortality-Related Factors After Hospitalization for Acute Exacerbation of COPD. Chest 2003; 124: 459-67.[CrossRef]

34. McEvoy CE, Niewoehner DE. Adverse effects of corticosteroid therapy for COPD: A critical review. Chest 1997; 111: 732-43. [CrossRef]

35. Tsai CL, Clark S, Cydulka RK, Rowe BH, Camargo CA Jr. Factors associated with hospital admission among emergency department patients with chronic obstructive pulmonary disease exacerbation. Acad Emerg Med 2007; 14: 6-14. [CrossRef]

36. Barnes PJ, Celli BR. Systemic manifestations and comorbidities of COPD. Eur Respir J 2009; 33: 1165-85. [CrossRef]

37. Sin DD, Anthonisen NR, Soriano JB, Agusti AG. Mortality in COPD: Role of comorbidities. Eur Respir J 2006; 28: 1245-57. [CrossRef]

38. Taşçı C, Arık D, Uçar E, Özkan M, Tozkoparan E, Bilgiç H. Retrospective evaluation of hospitalized COPD patients (One-year Follow-up).J Clin Anal Med 2011; 2: 4-6. [CrossRef]

39. Süreyyapaşa Chest Diseases and Chest Surgery Training and Research Hospital, Statistics for the year 2010. 